\title{
Pengaruh Asesmen Portofolio Disertai Pemberian CostructiveFeedback Terhadap Motivasi Belajar Mahasiswa Biologi FTIK IAIN Kerinci
}

\author{
Dewi Juita $^{1)}$, Yusmaridi. M $^{2)}$ \\ 1)Jurusan Tadris Biologi, FTIK IAIN Kerinci,Indonesia \\ 2)Jurusan Tadris Fisika, FTIK UIN Imam Bonjol Padang, Indonesia \\ dewijuita@iainkerinci.ac.id
}

\begin{abstract}
Research was triggered by the problem that encountered by researchers in the form of the learning motivation of students was low if the learning only used a discussion method in the lecture process. The purpose of this research was to determine the effect of the use of portfolio assessment accompanied by giving constructive feedback to learning motivation of students in scientific writing course. The research design that used was one group pre-test and post-test design. The sample in the research was the first semester of the B class in the Biology department, FTIK, IAIN Kerinci with the total numbers of students was 32 students. The instruments that used were learning motivation questionnaires of students that described from five indicators. Data from learning motivation results were analyzed through $<N$-Gain $>$ to determine the improvement for each indicator of learning motivation. The results of this research are indicators of perseverance, interest, and independence which have a high improvement while indicators of tenacity and achievement can classified into the moderate category.
\end{abstract}

Keywords : Portofolio, Constructive Feedback, Motivasi

This is an open access article distributed under the Creative Commons 4.0 Attribution License, which permits unrestricted use, distribution, and reproduction in any medium, provided the original work is properly cited. $@ 2018$ by author and Universitas Negeri Padang.

\section{PENDAHULUAN}

UU Nomor 2 Tahun 1989 pasal 16 ayat (1) tentang pendidikan tinggi menjelaskan bahwa perguruan tinggi merupakan kelanjutan pendidikan menengah yang diselenggarakan untuk menyiapkan peserta didik menjadi anggota masyarakat yang memiliki kemampuan akademik dan/atau profesional yang dapat menerapkan, mengembangkan dan/atau menciptakan ilmu pengetahuan, teknologi dan/atau kesenian. Sedangkan dalam PP 30 Tahun 1990 pasal 1 ayat 1 menjelaskan bahwa pendidikan tinggi adalah pendidikan pada jenjang yang lebih tinggi dari pada pendidikan menengah di jalur pendidikan sekolah.

Tujuan pendidikan tinggi menurut PP nomr 30 pasal 2 ayat 1 adalah:

1. menyiapkan peserta didik menjadi anggota masyarakat yang memiliki kemampuan akademik dan/atau profesional yang dapat menerapkan, mengembangkan dan/atau men ciptakan ilmu pengetahuan, teknologi dan/atau kesenian;

2. mengembangkan dan menyebarluaskan ilmu pengetahuan, teknologi dan/atau kesenian serta mengupayakan penggunaannya untuk meningkatkan taraf kehidupan masyarakat dan memperkaya kebudayaan nasional.

Pendidikan tinggi diselengarakan melalui kegiatan perkuliahan yang dilaksanakan oleh dosen dan mahasiswa. Selanjutnya PP Nomor 30 pasal 15 ayat 1 menjelaskan bahwa terhadap kegiatan dan kemajuan belajar mahasiswa dila kukan penilaian secara berkala yang dapat berbentuk ujian, pe;aksanaan tugas, dan peng amatan oleh dosen.

Penilaian dilakukan sesuai dengan $\mathrm{Ca}-$ paian pembelajaran yang dirumuskan oleh dosen pengampu mata kuliah. Setiap mata kuliah memiliki capaian pembelajaran yang berbeda-beda. Mata kuliah penulisan karya ilmiah memiliki capaian pembelajaran berupa: sikap (mahasiswa secara antusias mengikuti perkuliahan, mahasiswa menyelesaikan tugas secara mandiri), Pengetahuan (mahasiswa dapat memahami jenisjenis karya ilmiah, manfaat penyusunan karya ilmiah, memilih dan membatasi topik karya ilmiah, memilih judul karya ilmiah, kerangka karya ilmiah, menyunting dan mengetik karya ilmiah, sistematika penulisankarya ilmiah, serta menuliskan rujukan serta daftar pustaka untuk sebuah karya lmiah), dan keterampilan (menguasai berbagai teknik menyusun karya ilmiah). 
Untuk mencapai capaian pembelajaran tersebut maka dibutuhkan penilaian yang dapat mengukur semua kompetensi pada capaian tersebut. Capaian pembelajaran yang bagus akan didukung oleh motivasi belajar yang baik dari mahasiswa tentunya. Hal ini diperkuat oleh Sardiman (2014) yang mengatakan bahwa untuk belajar dengan baik diperlukan suatu proses dan motivasi yang baik juga.

Berdasarkan observasi yang peneliti lakukan pada 3 kali pertemuan pada mata kuliah penulisan karya ilmiah bahwa peneliti memperoleh gambaran bahwa motivasi belajar siswa masih rendah dalam melaksanakan perkuliahan. Hal ini dilihat dari beberapa indikator berupa :

1. Ketekunan dalam belajar

a. Kehadiran di Mata Kuliah

b. Mengikuti PBM di ruang kuliah

2. Ulet dalam menghadapi kesulitan

a. Sikap terhadap kesulitan

b. Usaha mengatasi kesulitan

3. Minat dan ketajaman perhatian dalam

Belajar

a. Kebiasaan dalam mengikuti perkuliahan

b. Semangat dalam mengikuti PBM

4. Berprestasi dalam belajar

a. Keinginan untuk berprestasi

b. Kualifikasi hasil

5. Mandiri dalam belajar

a. Penyelesaian tugas/PR

b. Menggunakan kesempatan di luar jam perkuliahan.

Persentase untuk masing-masing indikator yang penulis peroleh dengan menyebarkan angket motivasi belajar diperoleh bahwa 62,5\% maha siswa yang memiliki ketekunan dalam belajar, 40,6\% mahasiswa yang ulet dalam menghadapi kesulitan selama proses perkuliah an, 46,9\% mahasiswa yang memiiliki minat dan ketajaman perhatian dalam belajar, serta $43,75 \%$ maha siswa yang berprestasi dalam belajar, serta $56,25 \%$ mahasiswa yang mandiri dalam belajar. Rata-rata motivasi belajar mahasiswa dari lima indikator tersebut adalah 50\% yang mengindi kasikan bahwa setengah dari 32 mahasiswa memiliki motivasi yang tinggi dan setengahnya lagi memiliki motivasi yang rendah. Motivasi yang rendah ini akan memberikan dampak yang kurang baik terhadap pencapaian capaian pembe lajaran pada mata kuliah yang peneliti ajarkan.
Berdasarkan kondisi ini peneliti ingin memecahkan masalah motivasi mahasiswa yang rendah ini melalui penggunaan asesmen porto folio yang disertai dengan pemberian umpan balik (constructive feedback). Menurut Fajar dalam Ali (2016) menjelaskan bahwa asesmen portofolio merupakan pengajaran praktik dan mempunyai beberapa standar perencanaan yang kuat, yakni mendorong adanya interaksi antar lingkungan terkait seperti interaksi antar siswa, guru dan masyarakat yang saling melengkapi serta menggambarkan belajar siswa secara mendalam, yang pada akhirnya dapat membantu siswa menjadi sadar untuk meningkatkan dirinya sebagai pembaca dan penulis yang baik. Portofolio merupakan suatu cara agar dalam diri siswa tumbuh kepercayaan diri bahwa dia mampu mengerjakan tugas. Dengan tumbuhnya kepercayaan diri pada diri siswa diharapkan dapat memotivasinya untuk mencari pengeta huan dan pemahaman sendiri serta berkreasi dan terbuka ide-ide baru yang mereka lakukan kegiatan pembelajarnya. Berdasar pada kondisi mahasiswa tersebut maka dibutuhkan model asesmen yang dapat meningkatkan motivasi belajar mahasiswa.

Feedback merupakan bentuk komuni kasi dua arah antara dua atau lebih pihak. Hal ini diperkuat oleh Wilhelm L (2008) yang menya takan bahwa "The definition of feedback in organizations and business is ongoing, open twoway communication between". Tujuan dari pemberian feedback ini menurut Yasir Hamid (2010) adalah

It has two main objectives:

- to appreciate the good/right things with logical explanations

- identify the bad/wrong things and provide options to change them

Pemberian feedback memiliki tujuan agar tenaga pendidik dapat menghargai hal positif disertai dengan alasan yang logis serta untuk mengiden tifikasi hal negatif dan memberi solusi untuk memecahkan hal negatif tersebut.

Selanjutnya, Akalin \& Sucuoglu (2015) menjelaskan bahwa "Various studies have shown that the teachers' feedback have a positif impact on students' learning motivation, students' understanding, as well as the quality of student behavior". Pemberian feedback yang dilakukan oleh guru memberikan dampak posotif terhadap motivasi belajar siswa, pemahaman siswa.

Feedback itu ada yang bersifat membangun dan menghancurkan individu yang 
diberikan feedback. Hal ini diperkuat oleh Yasir Hamid (2010) yang mengatakan bahwa "The process of feedback can be negative or positive but the important thing is that it should be constructive and not destructive in nature".

Selanjutnya, Yasir Hamid (2010) juga berpendapat bahwa "Constructive feedback can be used as a tool for high quality learning and that in situations of incongruity between the actual and desired performances, the process of feedback may act a useful tool for students' growth and academic development". Umpan balik yang membangun dapat menghasil kualitas pembelajaran yang berkualitas serta bermanfaat untuk meningkatkan akademis siswa. Dari beberapa penjelasan diatas maka peneliti memperoleh suatu kesimpulan bahwa asesmen portofolio yang disertai dengan pemberian constructive feeback akan memberikan dampak yang positif untuk meningkatkan motivasi mahasiswa sehingga dapat meningkatkan pemahaman serta penguasaan mahasiswa terhadap materi kuliah yang peneliti ajarkan.

Mahasiswa selalu mengumulkan hasil kerja terbaiknya selama perkuliahan, dan nantinya dosen sebagai peneliti akan memberikan umpan balik yang membangun terkait hasil kerja mahasiswa sehingga mahasiswa akan lebih termotivasi dalam mengikuti perkuliahan yang diindikasikan dengan lima indikator yang sudah peneliti paparkan di bagian awal dari tulisan ini.

Tujuan dari penelitian ini adalah untuk melihat pengaruh asesmen portofolio disertai dengan pemberian constructive feedback terhadap motivasi belajar mahasiswa. Pengaruh yang penulis maksud adalah apakah terjadi peningkatan motivasi belajar mahasiswa sebelum dan sesudah perlakuan yang dianalisis menggunakan N-Gain.

Beberapa penelitian sudah dilakukan oleh beberapa peneliti diantaranya Khusaini (2017) yang membahas tentang penggunaan feedback pada kelas online yang peneliti tersebut bentuk, Ali Sadikin (2016) yang membahas tentang penggunaan asesmen porto folio dan jurnal belajar dalam meningkatkan kemampuan metakognitif dan motivasi belajar mahasiswa biologi. Posisi peneliti adalah peneliti ingin lebih meningkatkan motivasi belajar mahasiswa yang peneliti temui dengan memberikan umpan balik yang membangun kepada setiap mahasiswa sehingga dapat berujung pada peningkatan motivasi belajar yang lebih baik lagi dan dapat diterapkan di berbagai mata kuliah yang peneliti ampu ataupun pembaca yang telah membaca tulisan ini. Dengan perlakuan ini mahasiswa akan sadar atau mengetahui secara jelas dengan hasil kerjanya di setiap pertemuan sehingga dapat lebih meningkat dari pertemuan ke pertemuan berikutnya. Hal ini sesuai dengan pendapat Yasir Hamid (2010) yang mengatakan bahwa "constructive feedback increases self awareness, offers options and encourages development". Dengan demikian, pemberian constructive feed back dalam pembelajaran memberikan tiga keun tungan seperti dapat meningkatkan kesadaran diri sendiri, menawarkan pilihan-pilihan, dan mendorong pengembangan mahasiswa.

\section{METODE PENELITIAN}

Jenis penelitian yang digunakan dalam penelitian ini adalah penelitian kuantitatif. Penelitian kuantitatif merupakan penelitian yang berlandaskan fakta dan kebenaran semata. Hal ini diperkuat oleh Fraenkel, J.R (1993) yang menyatakan bahwa "quantitative researchers usually base their work on the belief that facts and feelings can be separated, that the world is a single reality made up of facts that can be discovered. Pendekatan yang digunakan adalah pendekatan eksperimen. Pendekatan eksperimen merupakan pendekatan penelitian dimana peneliti menerapkan suatu perlakuan dan hasil dari penelitian tersebut diinterpretasikan secara tepat. Ini sesuai dengan pendapat Fraenkel, J.R (1993) yang menyatakan bahwa "experimental research ...... actually establishes different treatments and the studies their effects, results from this type of research are likely to lead to the most clear-cut interpretations".

Metode penelitian yang digunakan adalah metode pre-experimental. Peneliti tidak menggunakan kelas pembanding. Desain peneli tian yang digunakan adalah One group pre-test post-test design. Desain ini tidak hanya menyelidiki hasil setelah diterapkannya suatu treatment akan tetapi juga ingin mengetahui hasil sebelum diterapkannnya. Fraenkel, J.R (1993) yang menyatakan bahwa "In the one-group pretest-posttest design, a single group is measured or observed not only after being exposed to a treatment of some sort, but also before". 

adalah:

Diagram dari desain penelitian ini

$$
\begin{array}{ccc}
\text { O } & \mathrm{X} & \mathrm{O} \\
\text { Pretest } & \text { Perlakuan } & \text { Posttest }
\end{array}
$$

Sebelum perlakuan, peneliti menyebarkan angket motivasi belajar mahasiswa dan setelah itu peneliti memberikan perlakuan berupa penggunaan asesmen portofolio dengan pemberi an constructive feeback dan terakhir peneliti menyebarkan angket motivasi kembali kepada mahasiswa sebagai bentuk hasil dari perlakuan yang telah peneliti lakukan.

Peningkatan motivasi belajar mahasiswa dianalisis dengan menggunakan nilai $\mathrm{N}-$ Gain dengan formula sebagai berikut:

$$
<N-\text { Gain }>=\frac{<\text { Posttest }>-<\operatorname{Pr} \text { etest }>}{S_{\text {maks } . \text { Ideal }}-<\operatorname{Pr} \text { etest }>}
$$

Keterangan:

\begin{tabular}{|c|c|c|}
\hline No. & Rentang & $\begin{array}{c}\text { Kategori } \\
\text { Rata-rata } \\
\text { Peningkatan }\end{array}$ \\
\hline 1. & $<\mathrm{N}-$ Gain $>\geq 0,7$ & Tinggi \\
\hline 2. & $\begin{array}{c}0,3 \leq<\text { N-Gain }>< \\
0,7\end{array}$ & Sedang \\
\hline 3. & $<$ N-Gain $><0,3$ & Rendah \\
\hline
\end{tabular}

$$
\begin{array}{ll}
\langle\text { Posttest }\rangle & =\text { Skor rata-rata posttest } \\
\langle\text { Pretest }\rangle & =\text { Skor rata-rata pretest } \\
\mathrm{S}_{\text {maks.ideal }} & =\text { Skor maksimum ideal }
\end{array}
$$

Tabel 1. Kategori <N-Gain>

(Hake, 1999)

\section{HASIL DAN PEMBAHASAN}

Dari hasil penelitian, peneliti memperoleh data bahwa terdapat $93,75 \%$ mahasiswa (30 mahasiswa) yang memiliki ketekunan dalam belajar, 78,12\% mahasiswa (25 mahasiswa) yang ulet dalam menghadapi kesulitan selama proses perkuliahan, 93,75\% mahasiswa (30 mahasiswa) yang memiliki minat dan ketajaman perhatian dalam belajar, serta $75 \%$ mahasiswa (24 mahasiswa) yang berprestasi dalam belajar, serta 90,62\% mahasiswa (29 mahasiswa) yang mandiri dalam belajar. Ratarata motivasi belajar mahasiswa dari lima indikator tersebut adalah $86,25 \%$. Cuplikan data motivasi belajar mahasiswa dapat dilihat pada Gambar 1 berikut.

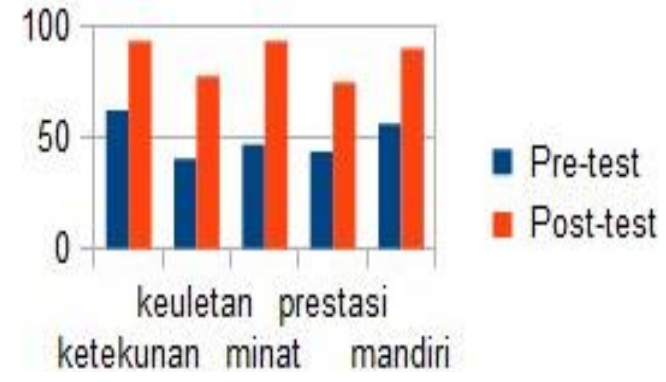

Gambar 1. Cuplikan Motivasi Belajar kuı Tiap Indikator

tinggi), nilai <N-Ǧain> untuk indikator ǔlet dalam menghadapi kesulitan selama proses perkuliahan adalah 0,63 (kategori sedang), nilai $<\mathrm{N}-$ Gain $>$ untuk indikator minat dan ketajaman perhatian dalam belajar adalah 0,88 (kategori tinggi), nilai <N-Gain> untuk indikator berpres tasi dalam belajar adalah 0,56 (kategori sedang), dan nilai <N-Gain>untuk indikator mandiri dalam belajar adalah 0,78 (kategori tinggi). Cuplikan nilai <N-Gain> untuk tiap indikator motivasi belajar ditunjukkan pada Gambar 2.

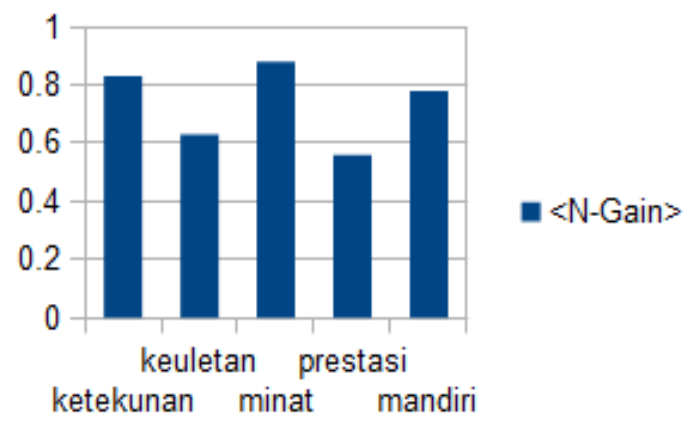

Gambar 2. Cuplikan Nilai <N-Gain> tiap Indikator Motivasi Belajar

Indikator ketekunan dalam belajar memiliki peningkatan dalam kategori tinggi yang meng indikasikan bahwa kehadiran mahasiswa mayori tas $100 \%$ sejak dilakukannya treatment tersebut. Mahasiswa lebih antusias untuk datang ke ruang kuliah untuk melaksanakan proses belajar meng ajar dikarenakan penilaian portofolio dilaksa nakan di setiap pertemuan sehingga maha siswa akan takut dan merasa kurang beruntung jika mereka tidak hadir maka penilaian tiap perte muan mereka di mata kuliah akan berkurang.

Selanjutnya, pada indikator ulet dalam menghadapi kesulitan memiliki peningkatan dalam kategori sedang. Hal ini disebabkan karena ketika terjadi kesulitan dalam kegiatan proses belajar mengajar ada beberapa maha siswa yang 
ingin memecahkannya langsung oleh dirinya sendiri dan ada juga yang menyelesaikan sambil menunggu usaha dari teman yang lain atau mennggu jawaban dosen pengampu. Akan tetapi, sebagian besar dari mahasiswa berani untuk memecahkan kesulitan dengan porotofolio yang mereka gunakan serta feedback yang diberikan oleh peneliti di setiap pertemuan dapat membangun konsep yang baik dalam diri siswa sehingga mahasiswa dapat mengatasi kesulitan yang ditemuinya baik secara klasikal maupun secara individual. Constructive feedback mem buat mereka lebih percaya diri untuk mampu menyelesaikan masalah ataupun kesulitan yang mereka temui.

Indikator minat dan ketajaman perhatian dalam belajar memiliki peningkatan dalam kategori tinggi. Hal ini disebabkan karena dengan menggunakan asesmen portofolio ini mahasiswa dapat lebih memfokuskan pemikiran nya terhadap topik tiap pertemuan. Mahasiswa memiliki semangat dalam kegiatan diskusi selama proses perkuliahan. Mereka dapat menyanggah ataupun mendukung jawaban dari pemakalah ataupun dosen pengampu selama proses perkuliahan berlangsung.

Indikator prestasi dalam belajar memi liki peningkatan dalam kategori sedang. Hal ini dapat terjadi karena faktor internal yang terdapat dalam diri mahasiswa itu sendiri. Dari hasil pemahaman mahasiswa mengenai konsep yang penulis lakukan masih terdapat hasil yang rendah, sementara dalam proses mahasiswa tersebut bersemangat dalam perkuliahan. Hal ini seharusnya peneliti teliti melalui komunikasi interpersonal. Akan tetapi, peneliti tidak memiliki waktu lagi untuk mewawancarai tiap mahasiswa tersebut yang memiliki prestasi yang tidak sesuai dengan yang penulis harapkan.

Indikator mandiri dalam belajar memi liki peningkatan dalam kategori tinggi. Maha siswa menyelesaikan tugasnya secara mandiri. Masing-masing mahasiswa dapat menampilkan kelebihannya dalam portofolio yang mereka kerjakan. Mahasiswa juga ada melalukan diskusi di luar kelas terkait dengan topik perkuliahan yang akan mereka bahas. Mereka berlombalomba menghasilkan karya terbaik terkait topik yang telah dijelaskan oleh peneliti.
Berdasarkan hasil penelitian ini, peneliti ingin memberikan beberapa saran berupa sebaiknya penelitian ini disertai dengan komu nikasi interpersonal yang dilakukan oleh tenaga pendidik dengan peserta didiknya agar lebih dapat mengetahui akar permasalahan yang sebenarnya. Selanjutnya, peneliti juga menyaran kan agar peneliti selanjutnya dapat membahas tentang bagaimana pengaruh asesmen portofolio dengan pemberian constructive feedback ini dalam penguasaan konsep serta indeks prestasi mahasiswa.

\section{KESIMPULAN}

Kesimpulan yang diperoleh dari penelitian ini adalah terdapat pengaruh asesmen portofolio disertai dengan pemberian constructive feedback terhadap motivasi belajar mahasiswa yang ditandai dengan terjadinya peningkatan yang tinggi pada beberapa indikator mtoivasi belajar mahasiswa yang berwujud dalam bentuk angket motivasi belajar.

\section{DAFTAR PUSTAKA}

Akalin, S., \& Sucuoglu, B. (2015). Effects of Classroom Management Intervention Based on Teacher Training and Performance Feedback on Outcomes of Teacher-Student Dyads in Inclusive Classrooms. Educational Sciences: Theory and Practice, 15(3), 739-758.

Fraenkel, J.R \& Wallen, N.E. (1993). How To Design And Evaluate Research in Education (second ed.). New York: McGraw-Hill Book Co.

Hake, R. (1999). Analyzing Change/Gain Scores. Indiana: Indiana University

Hamid, Y. (2010). Understanding Constructive feedback : A Commitment between Teachers and Students for Academic and Professional Development. Vol.60, No.3, March 2010

Peraturan Pemerintah Republik Indonesia Nomor 30 Tahun 1990 tentang Pendidikan Tinggi

Rahmi, Y. L., \& Alberida, H. (2017). Improving students' higher order thinking skills through portfolio assessment on biology curriculum and textbook analysis course. Bioeducation Journal, 1(1), 22-33. 
Sardiman. (2014). Interaction and TeachingLearning Motivation. Jakarta: Rajawali Pers

Sadikin, A., dkk. (2016). Penerapan Asesmen Berbasis Portofolio dan Jurnal Belajar untuk Meningkatkan Kemampuan Metakognitif dan Motivasi Belajar Mahasiswa pada Mata Kuliah Perencanaan Pengajaran Biologi. Jurnal Biodik Vol.II No 2 Desember 2016

Undang-undang Republik Indonesia Nomor 2 Tahun 1989 tentang Sistem Pendidikan Nasional

Wilhelm L. Characteristics of Good Constructive Feedback 2008. [Online] [Cited 2008]. Available from URL: http://www.articlesbase.com/communicati onarticles/ characteristics-of-good constructive-feedback-445867.html. 